\title{
Estudo citogenético das gônadas em pacientes com amenorréia primária
}

\author{
Gonadal cytogenetic analysis in patients with primary amenorrhea \\ Carla D’Agostini ${ }^{1}$, Rejane Gus ${ }^{2}$, Edison Capp ${ }^{3}$, Helena von Eye Corleta ${ }^{4}$
}

\section{RESUM0}

Introdução: pacientes em amenorréia primária com disgenesia gonadal têm níveis elevados de gonadotrofinas e necessitam de avaliação cromossômica. O estudo citogenético (cariótipo) pode ser realizado na gônada ou no sangue periférico. Nos casos de amenorréia primária sem sinal de virilização, a necessidade de investigação adicional do cariótipo da gônada não está estabelecida. Objetivo: revisar os cariótipos de gônadas (ovários) de mulheres com amenorréia primária e compará-los com os resultados do cariótipo no sangue periférico, relacionando-os às características fenotípicas das pacientes. Métodos: foram analisados retrospectivamente os dados clínicos e os cariótipos de doze pacientes atendidas no período de janeiro de 1997 a dezembro de 2003 no Hospital de Clínicas de Porto Alegre. Resultados: nas pacientes incluídas, quando o motivo da investigação foi amenorréia primária sem sinal de virilização, o cariótipo da gônada foi concordante com o cariótipo do sangue periférico nos oito casos avaliados (sete pacientes com cariótipo 46XX e uma paciente com cariótipo 46XY). A paciente oito foi a única com sinal de virilização (hipertrofia de clitóris) e o único caso de cariótipos discordantes. Conclusão: este estudo sugere que o cariótipo de gônada não traz informação adicional ao cariótipo do sangue periférico nas pacientes com amenorréia primária sem sinais de virilização. Até o momento todos os trabalhos publicados tiveram número pequeno de pacientes. A análise da relação custo-benefício pode permitir redução de estresse psicológico para paciente e familiares, bem como redução de custos para as instituições.

PALAVRAS-CHAVE: Amenorréia; Disgenesia gonadal; Cariótipo

\section{ABSTRACT}

Background: patients with primary amenorrhea and gonadal dysgenesia have higher serum gonadotrophins and should be submitted to chromosome studies. Karyotype studies may be performed in gonadal tissue or peripheral blood however, it is not yet established if cases of primary amenorrhea without signs of virilization need additional investigation of gonadal karyotype. Purpose: to analize the gonadal karyotypes (ovaries) from patients with primary amenorrhea and compare them to their respective peripheral blood karyotypes. Methods: clinical and karyotype data of 12 patients were retrospectively analyzed from January 1997 to December 2003. Results: when the investigation was indicated for primary amenorrhea without signs of virilization, the gonadal and peripheral blood karyotypes were concordant in 8 cases ( 7 cases 46XX and 1 case 46XY). One patient with virilization signs was the only case of discordant karyotype. Conclusion: the present study suggests that the gonadal karyotype does not bring additional information to peripheral blood karyotype in patients with amenorrhea and no signs of virilization. Although all previous studies had a small number of patients, it seems advisable to investigate the gonadal karyotype in patients with signs of virilization. The cost-benefit analysis could allow cost and stress reduction for patients, family and institutions.

KEYWORDS: Amenorrhea; Gonadal dysgenesia; Karyotype

Serviço de Ginecologia e Obstetrícia, Hospital de Clínicas de Porto Alegre, Universidade Federal do Rio Grande do Sul, Porto Alegre (RS).

1 Médica Residente do Departamento de Ginecologia e Obstetrícia, Hospital de Clínicas de Porto Alegre (RS).

2 Citogeneticista do Serviço de Genética Médica do Hospital de Clínicas de Porto Alegre (RS).

3 Professor Adjunto do Departamento de Ginecologia e Obstetrícia, Universidade Federal do Rio Grande do Sul (RS).

4 Prof Adjunto do Departamento de Ginecologia e Obstetrícia, Universidade Federal do Rio Grande do Sul (RS).

Correspondência: Helena Corleta

Rua Ramiro Barcelos, 910 cj 905 - 90035-001 - Porto Alegre - RS - Tel.: (51) 3311-5699 - Fax: (51) 3311-6588 - e-mail: hcorleta@portoweb.com.br Recebido em: 3/1/2005 Aceito com modificações em: 3/3/2005 
Introdução

O estabelecimento de dismorfismos sexuais implica uma série de eventos interligados que iniciam com a determinação sexual (definição da constituição cromossômica sexual do zigoto), seguida por diferenciação sexual e o desenvolvimento das gônadas correspondentes, da genitália interna e dos caracteres sexuais secundários. Alterações na estrutura ou número dos cromossomos sexuais podem alterar genes necessários à diferenciação sexual, originando anomalias do desenvolvimento que resultam numa gônada anômala ${ }^{1,2}$.

A realização de um cariótipo deve ser considerada em pacientes femininas com atraso puberal ou falha de crescimento. Deve ser utilizado também para excluir, por exemplo, síndrome de Turner em pacientes com fenótipo feminino e níveis elevados de FSH que apresentarem pequena estatura com velocidade do crescimento em declínio (velocidade de crescimento abaixo do percentil 10). $\mathrm{Na}$ adolescência pode-se considerar a realização de cariótipo naquelas pacientes sem desenvolvimento de mamas até a idade de 13 anos, com parada puberal e amenorréia primária ou secundária associada a niveis elevados de $\mathrm{FSH}^{3}$.

Múltiplos genes estão envolvidos na diferenciação sexual ${ }^{4}$. A presença do cromossomo Y (inteiro e normal) determina a diferenciação testicular. O gene responsável pelo fator determinante testicular é o SRY (sex region of the Y), que se encontra no braço curto do cromossomo $\mathrm{Y}^{5}$. Embora o SRY seja um gene-chave, o mesmo não atua isoladamente, mas em combinação com outros genes envolvidos em eventos regulatórios da diferenciação testicular ${ }^{6}$. A cascata que leva à determinação sexual constitui um modelo peculiar de mecanismos de regulação gênica que levam ao desenvolvimento do embrião. A descoberta da região determinante do sexo (SRY) no início da década de 90 foi a etapa crucial para o entendimento geral da determinação sexual. A partir dele, diversos genes que codificam proteínas envolvidas nesta cascata, tais como WT1 (Wilms' tumor gene), SF-1 (steroid factor-1), SOX9 (SRY related HMG BOX gene 9) e, DAX-1 (DSS - Adrenal hypoplasia congenita critical region on the $X$ chromosome gene 1), foram identificados. Muitas das interações entre estas proteínas ainda não foram elucidadas ${ }^{6}$.

As alterações gonadais resultam de uma anomalia do desenvolvimento durante a embriogênese, causada por aberrações cromossômicas como translocações, mosaicismos, mutações ou deleções em SRY, SOX9, SF-1, WT1 ou outras anomalias genéticas de ocorrência rara ${ }^{1,7}$.
Dentre as anomalias do desenvolvimento sexual feminino, a amenorréia primária é definida como a ausência do desenvolvimento de caracteres sexuais secundários até os 14 anos de idade ou ausência de menstruação até os 16 anos de idade, apesar da presença dos caracteres sexuais secundários ${ }^{8}$. Pacientes em amenorréia primária com disgenesia gonadal têm niveis elevados de gonadotrofinas e necessitam de avaliação cromossômica ${ }^{9}$.

Caso haja a presença do cromossomo Y no cariótipo da paciente, torna-se necessário a excisão gonadal, pois qualquer componente testicular em gônadas disgenéticas aumentará a chance de transformação maligna, estimada em $25 \%$ até os $30 \operatorname{anos}^{10}$. Embora os gonadoblastomas benignos sejam os tumores mais comumente encontrados nestes pacientes, há associação significativa com neoplasias malignas de células germinativas ${ }^{11}$. Aproximadamente $30 \%$ das pacientes com cromossomo Y não desenvolverão sinais de virilização. Portanto, mesmo uma mulher adulta com aparência normal deve ter seu cariótipo determinado se apresentar hipogonadismo hipergonadotrófico antes dos 30 anos $^{12}$. Quando sinais de virilização ocorrem e/ou existe um fragmento cromossômico de origem desconhecida, a despeito de um Y não identificado no cariótipo, o uso de sondas para identificação de material do Y é também indicado ${ }^{12}$.

O estudo citogenético (cariótipo) pode ser realizado na gônada ou no sangue periférico. Nos casos de amenorréia primária sem sinal de virilização, a necessidade de investigação adicional do cariótipo da gônada não está estabelecida.

O objetivo deste trabalho foi revisar os casos de cariótipos de gônadas (ovários) realizados no Laboratório de Citogenética do Serviço de Genética Médica do Hospital de Clínicas de Porto Alegre (HCPA) de 1997 a 2003 e compará-los com o resultado do cariótipo do sangue periférico, relacionando-os às características fenotípicas apresentadas pelas pacientes estudadas.

\section{Pacientes e Métodos}

No período de janeiro de 1997 a dezembro de 2003 foram realizados doze cariótipos de gônadas (ovários) no Laboratório de Citogenética do Serviço de Genética Médica do Hospital de Clínicas de Porto Alegre. Destes, foi possivel obter informações clínicas de apenas nove pacientes. Os prontuários foram revisados e informações sobre as características fenotipicas das pacientes, idade em que 
iniciaram a investigação e motivo da mesma, exames laboratoriais, resultados dos cariótipos de gônadas e do sangue periférico, bem como prováveis diagnósticos descritos em seus prontuários foram coletadas.

As biópsias foram obtidas e transportadas ao laboratório em meio de cultura apropriado e de maneira totalmente asséptica, e onde eram imediatamente processadas. Pequenos pedaços (explantes) eram retirados das biópsias e colocados cuidadosamente em frascos de cultura com meio Amniomax, ideal para o crescimento celular, e mantidas a $37^{\circ} \mathrm{C}$, em estufa de $\mathrm{CO}_{2}$. Ali permaneciam por 2 a 3 semanas. As culturas eram observadas diariamente e, ao atingirem o cresci- mento desejado, as células eram coletadas e passavam por um processo de hipotonia, fixação e coloração das células, para posterior análise dos cromossomos ao microscópio.

\section{Resultados}

Foram revisados os prontuários das nove pacientes incluidas no estudo, sendo que a causa que levou à realização do exame foi amenorréia primária em sete destas pacientes, genitália ambígua em uma paciente e infertilidade e amenorréia secundária em outra paciente (Tabela 1). Não foi possivel obter as informações clínicas de três pacientes.

Tabela 1 - Características clínicas e genotípicas das pacientes.

\begin{tabular}{|c|c|c|c|c|c|c|c|c|c|}
\hline Paciente & Idade & $\begin{array}{l}\text { Motivo da } \\
\text { investigação }\end{array}$ & Tanner & Virilização & Genitália interna & $\begin{array}{l}\text { Exames } \\
\text { laboratoriais }\end{array}$ & $\begin{array}{l}\text { Cariótipo do } \\
\text { sangue } \\
\text { periférico }\end{array}$ & $\begin{array}{l}\text { Cariótipo da } \\
\text { gônada }\end{array}$ & $\begin{array}{l}\text { Provável } \\
\text { diagnóstico }\end{array}$ \\
\hline 1 & 16 & Amenorréia primária & $\mathrm{M} 2 \mathrm{P} 4$ & não & $\begin{array}{l}\text { Útero rudimentar + } \\
\text { gônadas em fita }\end{array}$ & $\begin{array}{l}\text { Hipogonadismo } \\
\text { hipergonadotrófico }\end{array}$ & $46, X X$ & $46, X X$ & $\begin{array}{l}\text { Disgenesia } \\
\text { gonadal pura }\end{array}$ \\
\hline 2 & 29 & Amenorréia primária & M4P5 & não & $\begin{array}{l}\text { Útero rudimentar + } \\
\text { gônadas em fita }\end{array}$ & $\begin{array}{l}\text { Hipogonadismo } \\
\text { hipergonadotrófico }\end{array}$ & $46, X X$ & $46, X X$ & $\begin{array}{l}\text { Disgenesia } \\
\text { gonadal pura }\end{array}$ \\
\hline 3 & 17 & Amenorréia primária & M2P3 & não & $\begin{array}{l}\text { Útero rudimentar + } \\
\text { gônadas em fita }\end{array}$ & $\begin{array}{l}\text { Hipogonadismo } \\
\text { hipergonadotrófico }\end{array}$ & $46, X X$ & $46, X X$ & $\begin{array}{l}\text { Disgenesia } \\
\text { gonadal pura }\end{array}$ \\
\hline 4 & 26 & $\begin{array}{l}\text { Infertilidade + } \\
\text { amenorréia } \\
\text { secundária }\end{array}$ & $?$ & não & Útero normal & $\begin{array}{l}\text { Hipogonadismo } \\
\text { hipergonadotrófico }\end{array}$ & $46, X X$ & $46, X X$ & $\begin{array}{l}\text { Falência } \\
\text { ovariana } \\
\text { precoce }\end{array}$ \\
\hline 5 & 16 & Amenorréia Primária & $\mathrm{M} 2 \mathrm{P} ?$ & não & Útero e ovários ausentes & $?$ & $46, X Y$ & $46, X Y$ & $\begin{array}{l}\text { Testículos } \\
\text { feminilizantes }\end{array}$ \\
\hline 6 & 32 & Amenorréia primária & M5P5 & não & Útero e ovários normais & $\begin{array}{l}\text { Hipogonadismo } \\
\text { hipogonadotrófico }\end{array}$ & $46, X X$ & $46, X X$ & Causa central \\
\hline 7 & 17 & Amenorréia primária & $\mathrm{M} 2 \mathrm{P} 2$ & não & $\begin{array}{l}\text { Útero normal/um ovário } \\
\text { atrésico e outro com } \\
\text { teratoma }\end{array}$ & $\begin{array}{l}\text { Hipogonadismo } \\
\text { hipergonadotrófico }\end{array}$ & $46, X X$ & $46, X X$ & $\begin{array}{l}\text { Disgenesia } \\
\text { gonadal }\end{array}$ \\
\hline 8 & 8 & Genitália ambígua & M1P1 & $\begin{array}{l}\text { hipertrofia } \\
\text { de clítoris }\end{array}$ & Útero e ovários presentes & $?$ & $45, X / 46, X Y$ & $45, X$ & $\begin{array}{l}\text { Disgenesia } \\
\text { gonadal }\end{array}$ \\
\hline 9 & 19 & Amenorréia primária & M1P2 & não & Útero rudimentar & $\begin{array}{l}\text { Hipogonadismo } \\
\text { hipergonadotrófico }\end{array}$ & $46, X Y$ & $46, X Y$ & $\begin{array}{l}\text { Disgenesia } \\
\text { gonadal }\end{array}$ \\
\hline
\end{tabular}

?: Informação omitida no prontuário

Pôde-se observar que nas pacientes estudadas (Tabela 1), quando o motivo da investigação foi amenorréia primária (apenas um caso de amenorréia secundária) e não havendo sinal de virilização, o cariótipo de gônada foi concordante com o cariótipo do sangue periférico nos oito casos avaliados (sete pacientes com cariótipo 46,XX e uma paciente com cariótipo $46, \mathrm{XY}$ ). A paciente oito foi a única com sinal de virilização (hipertrofia de clitóris) e o único caso de cariótipos discordantes entre sangue periférico e gônada. Neste caso, evidenciou-se mosaicismo (45,X) $46, \mathrm{XY})$ no sangue periférico e monossomia do $\mathrm{X}$ $(45, X)$ na gônada. 


\section{Discussão}

Os dados apresentados não demonstraram alteração do diagnóstico após realização de cariótipo da gônada, ou seja, não houve informação adicional ao cariótipo do sangue periférico nas pacientes com amenorréia primária sem sinais de virilização. Usualmente, estudos comparando o cariótipo do sangue periférico e das gônadas são limitados pelo número pequeno de pacientes ${ }^{13,14}$.

Quando da realização do cariótipo gonadal, devem ser considerados os riscos e os custos do procedimento. Neste estudo, 8 das 9 pacientes estudadas tiveram amostra gonadal coletada mediante videolaparoscopia, procedimento com baixo índice de complicações, porém dependente da experiência do operador. Nas pacientes estudadas não houve registro de complicações do procedimento. A única paciente submetida à laparotomia teve como indicação uma massa anexial direita complexa (teratoma imaturo), sendo que a coleta de material para realização do cariótipo gonadal foi realizada no mesmo procedimento. Houve custo adicional não desprezivel para a avaliação do cariótipo gonadal pela videolaparoscopia diagnóstica realizada em caráter ambulatorial.

A disgenesia gonadal 46XX sem a presença de $\mathrm{Y}$ associado a tumores germinativo ${ }^{15-17}$ tem levantado a questão sobre a indicação de gonadectomia bilateral de gônadas disgenéticas. Em nossa amostra, a paciente 7 (Tabela 1) com cariótipo 46XX foi operada por tumor germinativo ovariano, teratoma imaturo. Contudo, a gonadectomia não é isenta de riscos e há casos de gônadas com alguma função residual e até mesmo gestações em pacientes com disgenesia gonadal ${ }^{16}$, justificando a preservação das gônadas em disgenesias gonadais 46,XX sem alterações fenotípicas.

Recentemente, técnicas de biologia molecular visando detectar seqüências provenientes do cromossomo Y por PCR refinaram a propedêutica dos pacientes com disgenesia gonadal. Por exemplo, 3 a 4\% das pacientes 45, XO têm fragmentos de Y detectados por PCR, sendo considerada baixa a incidência de mosaicismo não detectado pela análise citogenética ${ }^{18}$. Mesmo com análise por PCR, persiste a dúvida sobre quais pacientes com disgenesia gonadal devem realizar PCR para detecção de fragmentos do cromossomo Y e se é necessário identificar a presença de mosaicismo silente ${ }^{12}$. Outro problema relacionado às técnicas de biologia molecular é que esta abordagem identifica apenas as seqüências de
DNA correspondentes a sondas específicas, podendo haver seqüências não previstas. Por isto, atualmente, a recomendação para investigar fragmentos de cromossomo Y por técnicas de biologia molecular é restrita a pacientes com sinais de virilização ou àquelas em que o estudo citogenético foi sugestivo de fragmentos de cromossomo $\mathrm{Y}^{3}$.

Nas pacientes incluídas no estudo, a realização do cariótipo da gônada não modificou o diagnóstico inicial quanto ao tipo de disgenesia gonadal e também não detectou a presença de cromossomo $Y$ que justificasse a necessidade de remoção das gônadas. A recomendação mais recente quanto à investigação de disgenesia gonadal é concordante com nossos dados. Não fazem referência ao cariótipo de gônada e sim, em casos selecionados, a técnicas de biologia molecular, como PCR ou nested PCR, em sangue periférico para, por exemplo, identificar mosaicismo de cromossomo $\mathrm{Y}^{3}$.

Assim, este estudo sugere que a investigação com cariótipo das gônadas na amenorréia primária parece não trazer informação adicional ao cariótipo do sangue periférico nas pacientes sem alterações fenotípicas, situação esta que se altera nos casos de virilização. Apesar de os trabalhos publicados sobre este assunto terem número pequeno de pacientes, a possibilidade de identificar a presença de cromossomo $\mathrm{Y}$ e mosaicismos no sangue periférico parece tornar desnecessária a análise citogenética da gônada.

\section{Referências}

1. Chemes H, Muzulin PM, Venara MC, Mulhmann MC, Martinez M, Gamboni M. Early manifestations of testicular dysgenesis in children: pathological phenotypes, karyotype correlations and precursor stages of tumour development. APMIS. 2003;111(1):12-23.

2. Achermann JC, Ozisik G, Meeks JJ, Jameson JL. Genetic causes of human reproductive disease. J Clin Endocrinol Metab. 2002;87(6):2447-54.

3. Saenger P, Wikland KA, Conway GS, Davenport M, Gravholt $\mathrm{CH}$, Hintz R, et al. Recommendations for the diagnosis and management of Turner syndrome. J Clin Endocrinol Metab. 2001;86(7):3061-9.

4. Tho SP, Layman LC, Lanclos KD, Plouffe L Jr, Byrd JR, McDonough PG. Absence of the testicular determining factor gene SRY in XX true hermaphrodites and presence of this locus in most subjects with gonadal dysgenesis caused by $\mathrm{Y}$ aneuploidy. Am J Obstet Gynecol. 1992;167(6):1794-802.

5. Sinclair AH, Berta P, Palmer MS, Hawkins JR, Griffiths BL, Smith MJ, et al. A gene from the human sex-determining region encodes a protein with 
homology to a conserved DNA-binding motif. Nature. 1990;346(6281):240-4.

6. Vaiman D, Pailhoux E. Mammalian sex reversal and intersexuality: deciphering the sex-determination cascade. Trends Genet. 2000;16(11):488-94.

7. Schaffler A, Barth N, Winkler K, Zietz B, Rummele $\mathrm{P}$, Knuchel $\mathrm{R}$, et al. Identification of a new missense mutation (Gly95Glu) in a highly conserved codon within the high-mobility group box of the sexdetermining region $\mathrm{Y}$ gene: report on a 46, XY female with gonadal dysgenesis and yolk-sac tumor. J Clin Endocrinol Metab. 2000;85(6):2287-92.

8. Skull J. Amenorrhoea. Curr Obstet Gynaecol. 2001;11(4):225-32.

9. Mashchak CA, Kletzky OA, Davajan V, Mishell DR Jr. Clinical and laboratory evaluation of patients with primary amenorrhea. Obstet Gynecol. 1981;57(6):715-21.

10.Manuel M, Katayama PK, Jones HW Jr. The age of occurrence of gonadal tumors in intersex patients with a Y chromosome. Am J Obstet Gynecol. 1976;124(3):293-300.

11. Troche V, Hernandez E. Neoplasia arising in dysgenetic gonads. Obstet Gynecol Surv. 1986;41(2):74-9.

12.Speroff L, Fritz MA. Normal and abnormal sexual development. In: Speroff L, Fritz MA, editors. Clinical gynecologic endocrinology and infertility. Philadelphia: Lippincott Williams \& Wilkins; 2005. p. 32059.
13. Surico N, Messina M, Ponzio G, Libanori E, Chiodo F, Milani, et al. Limited diagnostic value of lymphocytic karyotype in primary amenorrhea with streak gonads. Eur J Obstet Gynecol Reprod Biol. 1987;26(2):145-50.

14.Ropke A, Pelz AF, Volleth M, Schlosser HW, Morlot $\mathrm{S}$, Wieacker PF. Sex chromosomal mosaicism in the gonads of patients with gonadal dysgenesis, but normal female or male karyotypes in lymphocytes. Am J Obstet Gynecol. 2004;190(4):1059-62.

15.Steinhardt GF, Ine MY, Subramanian MG, Hukku B, Perrin EV, Hoffman WH. Gonadoblastoma presenting as isosexual precocious puberty in a genetic female. J Pediatr Surg. 1986;21(10):905-7.

16.Zhao S, Kato N, Endoh Y, Jin Z, Ajioka Y, Motoyama T. Ovarian gonadoblastoma with mixed germ cell tumor in a woman with 46, XX karyotype and successful pregnancies. Pathol Int. 2000;50(4):332-5.

17. Morimura Y, Nishiyama H, Yanagida K, Sato A. Dysgerminoma with syncytiotrophoblastic giant cells arising from 46, XX pure gonadal dysgenesis. Obstet Gynecol. 1998;92(4 Pt 2):654-6.

18.Binder G, Koch A, Wajs E, Ranke MB. Nested polymerase chain reaction study of 53 cases with Turner's syndrome: is cytogenetically undetected Y mosaicism common? J Clin Endocrinol Metab. 1995;80(12):3532-6. 